\title{
PERILAKU PENGGUNAAN GADGET DI ERA NEW NORMAL DENGAN KUALITAS TIDUR PADA REMAJA DI SMPN 2 ABUNG SELATAN KABUPATEN LAMPUNG UTARA
}

\author{
Dian Utama Pratiwi Putri ${ }^{1}$, Nadya Chairunissa ${ }^{2}$ \\ Afialiasi $^{1,2}$, Program Universitas Mitra Indonesia \\ dian@umitra.ac.id
}

\begin{abstract}
Abstrak
Salah satu masalah kesehatan pada remaja adalah masih kurangnya pemenuhan kualitas tidur pada remaja. Penelitian epidemiologi di Indonesia didapatkan prevalensi kualitas tidur yang buruk sebesar 73,4\%. Salah satu faktor yang menyebabkan remaja mengalami kualitas tidur yang buruk diantaranya adalah perubahan gaya hidup termasuk penggunaan gadget ditambah lagi di era pandemic saat ini banyak remaja yang menjalankan pembelajaran secara daring sehingga menyebabkan pengggunaan gadget yang berlebihan. Tujuan penelitian ini adalah mengetahui hubungan perilaku penggunaan gadget di era new normal dengan kualitas tidur pada remaja di SMPN 2 Abung Selatan Kabupaten Lampung Utara Tahun 2020. Metode penelitian ini menggunakan jenis penelitian analitik observasional dengan pendekatan cross sectional. Subjek penelitian adalah seluruh remaja kelas VII dan VIII SMPN 2 Abung Selatan Kabupaten Lampung Utara, dengan jumlah sampel sebanyak 160 responden. Teknik sampling menggunakan proportional random sampling. Uji hipotesis menggunakan chi-square. Hasil analisis univariat diperoleh bahwa sebagian besar perilaku penggunaan gadget pada responden dalam kategori sedang, yaitu sebanyak 88 orang $(55,0 \%)$, sebagian besar responden memiliki kualitas tidur yang buruk, yaitu sebanyak 97 orang $(60,6 \%)$. Analisa bivariat diperoleh bahwa terdapat hubungan perilaku penggunaan gadget di era new normal dengan kualitas tidur pada remaja di SMPN 2 Abung Selatan Kabupaten Lampung Utara Tahun 2020 ( $\mathrm{p}$-value $=0,000$ dan $\mathrm{OR}=3,533$ ). Saran bagi tenaga kesehatan untuk melakukan pendidikan kesehatan di sekolah- sekolah terkait dengan kualitas tidur remaja dan dampak penggunaan gadget yang berlebihan di era new normal.
\end{abstract}

Kata kunci: Kualitas Tidur, Penggunaan Gadget, Era new normal, Remaja

\begin{abstract}
One of the health problems in adolescents is the lack of fulfillment of sleep quality in adolescents. Epidemiological research in Indonesia found that the prevalence of poor sleep quality was $73.4 \%$. One factor that causes teens to experience poor sleep quality include lifestyle changes including the use of gadgets. The purpose of this study is the relationship between the behavior of the use of gadgets in new normal era with sleep quality in adolescents at SMPN 2 Abung Selatan, North Lampung District in 2020. This research method uses observational analytic research with cross sectional approach. The subjects of the study were all class VII and VIII teenagers of SMPN 2 Abung Selatan, North Lampung District, with a total sample of 160 respondents. The sampling technique uses proportional random sampling. Hypothesis testing uses chi-square. Univariate analysis results obtained that the majority of gadget use behavior among respondents in the medium category, as many as 88 people (55.0\%), the majority of respondents had poor sleep quality, as many as 97 people (60.6\%). Bivariate analysis was obtained that there was a correlation between the behavior of using gadgets with sleep quality in adolescents at SMPN 2 Abung Selatan, North Lampung District in 2020 (p-value =0,000 and OR = 3,533). Suggestions for health workers to conduct health education in schools related to adolescent sleep quality and the impact of excessive gadget use in new normal era
\end{abstract}

Keywords: Sleep Quality, Use of Gadgets, New normal era, Adolescent 


\section{PENDAHULUAN}

Remaja merupakan masa transisi antara masa kanak-kanak menuju masa dewasa yang terjadi antara umur 13 dan 20 tahun. Pada masa remaja terjadi banyak perkembangan seperti perubahan fisik, kognitif dan psikososial. Selain perubahan fisik remaja juga mengalami perubahan kognitif yaitu perubahan pada pikiran dan lingkungan sosial remaja yang akan menghasilkan tingkat perkembangan intelektual. Pada perkembangan psikososial remaja akan mencari jati diri dengan membentuk hubungan kelompok yang erat (Potter \& Perry, 2012).

Masalah remaja lainnya adalah masih kurangnya pemenuhan kualitas tidur pada remaja. Tidur merupakan suatu keadaan berulang-ulang, perubahan status kesadaran yang terjadi selama periode tertentu. Tidur memiliki fungsi yang sangat penting untuk pemenuhan kognitif masa remaja. (Potter \& Perry, 2012).

Berdasarkan penelitian yang dilakukan oleh Bruni dkk tentang kualitas tidur dengan menggunakan metode Sleep Disturbances Scale for Children didapatkan prevalensi kualitas tidur yang buruk (sebagian besar pada gangguan transisi tidur-bangun) pada populasi kontrol adalah sebesar 73,4\% (Haryono, 2009).

Salah satu faktor yang menyebabkan remaja mengalami kualitas tidur yang buruk diantaranya adalah perubahan gaya hidup termasuk penggunaan gadget. Saat ini banyak remaja yang selalu memegang gadgetnya bahkan saat akan tidur sekalipun. Kondisi ini tentu saja akan menggangu kehidupan sosial dan kesehatan remaja (Linggasari, 2014).

Banyak remaja saat ini yang kecanduan gadget. Berdasarkan data terdapat sebanyak 30 juta atau sekitar $80 \%$ anak-anak dan remaja di Indonesia merupakan pengguna gadget (internet, dan media digital). Lebih dari setengah responden (52 persen) menggunakan ponsel untuk mengakses internet (Kemkominfo, 2017).

Dampak penggunaan gadget secara berlebihan tidak hanya mengurangi kualitas tidur pada remaja. media sosial yang ada pada gadget membuat remaja lebih senang berkomunikasi melalui media sosial dengan temannya dibandingkan dengan belajar. Gadget juga memudahkan remaja untuyk mengakses situs yang tidak seharusnya seperti dalam bentuk video kekerasan ataupun pornografi yang dapat menimbulkan berbagai kejahatan seperti penculikan dan pemerkosaan yang diawali dengan perkenalan di media sosial (Damayanti, 2017).

Berdasarkan hasil dari pre survey yang dilakukan oleh peneliti pada tanggal 8 Mei 2020 di SMPN 2 Abung Selatan Kabupaten Lampung Utara dan SMPN 1 Kotabumi Lampung Utara Tahun 2020.

Hasil wawancara terhadap 10 orang siswa di SMPN 2 Abung Selatan Kabupaten Lampung Utara, sebanyak 8 orang (80\%) mengalami tanda-tanda kualitas tidur yang buruk. Selain itu, dari 10 remaja, sebanyak 7 orang $(70 \%)$ menyatakan meggunakan gadget $>4$ jam dalam sehari. Sedangkan di SMPN 1 Kotabumi Lampung Utara dari 10 siswa, sebanyak 6 orang (60\%) yang mengalami tanda- tanda kualitas tidur yang buruk dengan jumlah remaja yang berlebihan dalam menggunakan gadget sebanyak 5 orang (50\%). 
Berdasarkan dari latar belakang yang telah di kemukakan diatas, maka yang menjadi permasalahannya adalah "Apakah ada hubungan perilaku penggunaan gadget dengan kualitas tidur pada remaja di SMPN 2 Abung Selatan Kabupaten Lampung Utara Tahun 2020?'.

Tujuan dilakukan penelitian ini untuk mengetahui hubungan perilaku penggunaan gadget di era new normal dengan kualitas tidur pada remaja di SMPN 2 Abung Selatan Kabupaten Lampung Utara Tahun 2020.

\section{METODE PENELITIAN}

Penelitian ini termasuk penelitian kuantitatif menggunakan desain analitik observasional dengan pendekatan cross sectional yang dilaksanakan pada bulan Juni tahun 2020 di SMP Negeri 2 Abung Selatan Kabupaten Lampung Utara. Populasi dalam penelitian ini adalah seluruh remaja kelas VII dan VIII yaitu sebanyak 267 orang. Sampel dalam penelitian ini adalah 160 responden yang memiliki gadget dengan teknik proportional random sampling (Notoatmodjo, 2014).

Pengumpulan data dilakukan dengan menggunakan kuesioner Pittsburgh Sleep Quality Indeks (PSQI) sebanyak 9 pertanyaan dan kuesioner Smartphone Addiction Scale (SAS) sebanyak 21 soal. Data diolah dengan langkah-langkah: editing, coding, processing, dan cleaning (Notoatmodjo, 2014).

Analisa data terdiri dari analisa univariat dan bivariat. Analisa univariat digunakan untuk menjelaskan atau mendeskripsikan karakteristik setiap variabel penelitian dan analisa bivariat dilakukan untuk melihat hubungan antar variabel. Penelitian ini menggunakan uji Chi-square dengan taraf yang digunakan adalah $5 \%$ atau $\mathrm{P}$ value 0,05 .

\section{HASIL DAN PEMBAHASAN}

Berdasarkan hasil penelitian yang telah dilakukan terhadap 160 responden, didapatkan hasil sebagai berikut:

Tabel 1. Distribusi Frekuensi Perilaku Penggunaan Gadget Pada Remaja

\begin{tabular}{ccc}
\hline $\begin{array}{c}\text { Penggunaan } \\
\text { Gadget }\end{array}$ & $\begin{array}{c}\text { Frekuensi } \\
(\mathbf{F})\end{array}$ & $\begin{array}{c}\text { Presentase } \\
(\boldsymbol{\%})\end{array}$ \\
\hline Rendah & 72 & 45.0 \\
Sedang & 88 & 55,0 \\
Tinggi & 0 & 0 \\
Total & 160 & 100 \\
\hline
\end{tabular}

Berdasarkan tabel 1 menunjukkan bahwa sebagian besar perilaku penggunaan gadget pada responden dalam kategori sedang, yaitu sebanyak 88 orang (55,0\%). Sedangkan responden yang memiliki penggunaan gadget dalam kategori rendah sebanyak 72 orang (45\%). 
Tabel 2. Distribusi Frekuensi Kualitas Tidur Pada Remaja

\begin{tabular}{ccc}
\hline Kualitas Tidur & Frekuensi (F) & Presentase (\%) \\
Baik & 63 & 39,4 \\
Buruk & 97 & 60,6 \\
\hline Total & 160 & \\
\hline
\end{tabular}

Berdasarkan tabel 2 menunjukkan bahwa sebagian besar responden memiliki kualitas tidur yang buruk, yaitu sebanyak 97 orang $(60,6 \%)$. Sedangkan responden yang memiliki kualitas tidur yang baik sebanyak 63 orang $(39,4 \%)$.

Berdasarkan 72 responden dengan perilaku penggunaan gadget yang rendah, terdapat 40 orang $(55,6 \%)$ yang memiliki kualitas tidur baik sedangkan sebanyak 32 orang $(44,4 \%)$ memiliki kualitas tidur yang buruk. Dari 88 responden dengan perilaku penggunaan gadget kategori sedang, terdapat 23 orang $(26,2 \%)$ yang memiliki kualitas tidur baik sedangkan sebanyak 65 orang $(73,9 \%)$ yang memiliki kualitas tidur buruk.

\section{Pembahasan \\ Distribusi Frekuensi Perilaku Penggunaan Gadget di era new normal Pada Remaja}

Berdasarkan hasil penelitian diperoleh bahwa sebagian besar perilaku penggunaan gadget pada responden dalam kategori sedang, yaitu sebanyak 88 orang $(55,0 \%)$. Hasil penelitian ini sesuai dengan teori yang dikemukakan oleh Widiawati (2014), bahwa gadget merupakan barang canggih yang diciptakan dengan berbagai aplikasi yang dapat menyajikan berbagai media berita, jejaring sosial, hobi, bahkan hiburan. Menurut Damayanti (2017), bahwa dampak penggunaan gadget antara lain yaitu pada remaja menggunakan media sosial didalam gadget mereka, sehingga menimbulkan lebih banyak waktu yang digunakan untuk bermain gadget. Walaupun perilaku penggunaan gadget sebagian besar kategori sedang, tentu ada pengaruh terhadap kualitas tidur, sehingga perlu dijadikan bahan perhatian agar perilaku dalam penggunaan gadget dapat diperbaiki. Bahwasanya bermain gadget tidak hanya menggangu jadwal tidur melainkan jika terlalu lama bertatapan dengan layar gadget pada waktu lama maka akan sulit untuk tertidur karena sinar biru yang menyerupai cahaya pada siang hari. (Hidayat, 2007 dalam Permadi, 2017). Hasil penelitian ini sejalan dengan penelitian yang dilakukan oleh Permadi (2017) tentang hubungan perilaku penggunaan gadget dengan kualitas tidur pada anak usia remaja di SMA Negeri 1

Srandakan Bantul, yang menyebutkan sebanyak 51\% remaja menggunakan gadget dalam ketegori sedang. Menurut pendapat peneliti sebagian besar responden memiliki perilaku penggunaan gadget dalam kategori sedang disebabkan karena gadget telah mempengaruhi setiap aspek remaja dimana pada usia remaja tersebut mereka mulai diberi kepercayaan untuk memiliki gadget sendiri dan sebagian besar telah memiliki ketergantungan pada gadget.

Ketergantungan gadget tersebut terus meningkat pada remaja sehingga mengganggu berbagai kegiatan seperti belajar ataupun aktivitas fisik yang seharusnya dilakukan karena terlalu asyik dalam menggunakan gadget, sehingga sampai kehilangan konsentrasi di kelas, saat melakukan tugas karena kecanduannya kepada gadget. 
Remaja menjadikan gadget sebagai kebutuhan hingga mengakibatkan mereka sering lupa waktu dan melakukan aktivitas penggunaan gadget hingga larut malam misalnya mereka terus-menerus memeriksa gadget agar tidak ketinggalan percakapan antara orang lain di media sosialnya.

\section{Distribusi Frekuensi Kualitas Tidur Pada Remaja}

Berdasarkan hasil penelitian diperoleh bahwa sebagian besar responden memiliki kualitas tidur yang buruk, yaitu sebanyak 97 orang $(60,6 \%)$. Hasil penelitian ini sesuai dengan teori yang dikemukakan oleh Potter \& Perry (2012) mendefinisikan tidur merupakan suatu keadaan berulang-ulang, perubahan status kesadaran yang terjadi selama periode tertentu. Tidur yang cukup dapat memulihkan tenaga. Tidur dapat memberikan waktu untuk perbaikan dan penyembuhan sistem tubuh untuk periode keterjagaan berikutnya.

Menurut Potter \& Perry (2012), sejumlah faktor mempengaruhi kuantitas dan kualitas tidur. Sering kali faktor tunggal tidak hanya menjadi penyebab masalah tidur. Faktor fisiologis, psikologis, dan lingkungan dapat mengubah kualitas dan kuantitas tidur antara lain: penyakit fisik; obat-obatan dan substansi; gaya hidup; stres emosional; lingkungan; latihan fisik dan kelelahan; asupan makanan dan kalori.

Hasil penelitian ini sejalan dengan penelitian yang dilakukan oleh Jarmi (2017), tentang hubungan penggunaan gadget dengan kualitas tidur pada remaja, berdasarkan hasil penelitian diperoleh bahwa bahwa kualitas tidur pada kategori buruk sebanyak 49 orang $(53,3 \%)$ sedangkan responden yang memiliki kualitas tidur yang baik sebanyak 43 orang $(46,7 \%)$.

Menurut pendapat peneliti sebagian besar responden memiliki kualitas tidur yang buruk disebabkan karena kebiasaan menggunakan gadget secara berkesinambungan atau terus menerus sehingga ditakutkan akan berlebihan dan menyebabkan terganggunya konsenterasi dan mempengaruhi kehidupan sehari-hari sehingga dapat mengganggu kualitas tidur. Disamping itu kualitas tidur dapat juga disebabkan oleh faktor lainnya faktor lain misalnya lingkungan yang bising; latihan fisik dan kelelahan akibat aktivitas di Sekolah.

\section{Hubungan Perilaku Penggunaan Gadget di era new normal Dengan Kualitas Tidur Pada Remaja}

Berdasarkan hasil penelitian diperoleh bahwa terdapat hubungan perilaku penggunaan gadget di era new normal dengan kualitas tidur pada remaja di SMPN 2 Abung Selatan Kabupaten Lampung Utara Tahun 2020 ( $p$-value $=0,000$ dan $\mathrm{OR}=3,533$ ).

Hasil penelitian ini sesuai dengan teori yang dikemukakan oleh Kariyadi (2015), bahwa gadget bisa dibilang sudah menjadi gaya hidup mereka sehari-hari, bahkan remaja tidak bisa hidup dan terlepas dari gadget. Gaya hidup seseorang sangat berpengaruh terhadap pola tidur seseorang. Hal ini dikarenakan rutinitas seseorang di siang hari akan mempengaruhi istirahatnya pada malam hari.

Menurut pendapat peneliti adanya hubungan perilaku penggunaan gadget di era new normal dengan kualitas tidur pada remaja di SMPN 2 Abung Selatan Kabupaten Lampung Utara Tahun 2020 disebabkan karena penggunaan gadget terlebih saat malam hari akan menggangu jadwal tidur seseorang, selain itu jika terlalu lama bertatapan dengan layar gadget dalam waktu lama maka akan menimbulkan kesulitan untuk tertidur karena sinar biru yang 
menyerupai cahaya pada siang hari menyebabkan seseorang tetap terjaga, dimana tubuh akan sesorang akan mudah mengantuk jika dalam keadaan cahaya redup. Hal ini terlihat dari hasil penelitian dimana proporsi responden dengan perilaku penggunaan gadget rendah cenderung memiliki kualitas tidur baik $(55,6 \%)$. Selain itu, responden dengan perilaku penggunaan gadget sedang cenderung memiliki kualitas tidur buruk $(73,9 \%)$.

\section{KESIMPULAN}

Hasil uji statistic diperoleh hasil nilai $\mathrm{p}=0,000$ maka dapat disimpulkan bahwa ada hubungan antara perilaku penggunaan gadget dengan kualitas tidur pada remaja di SMPN 2 Abung Selatan Kabupaten Lampung Utara. Dari hasil analisis diperoleh pula nilai OR=3,533 maka dapat disimpulkan bahwa remaja dengan perilaku penggunaan gadget tidak baik memiliki risiko 4 kali mengalami kualitas tidur yang buruk dibanding dengan remaja dengan perilaku penggunaan gadget yang baik. Hasil penelitian ini hendaknya dapat dijadikan dasar untuk orang tua dalam memberikan aturan mengenai jam tidur anak dan membatasi jangka waktu penggunaan gadget pada anak remaja.

\section{DAFTAR PUSTAKA}

Damayati, dkk. (2017). Hubungan Penggunaan Gadget Dengan Pencapaian Tugas Perkembangan Anak Usia Remaja Awal Di Kecamatan Godean. Jurnal UMY. Tidak diterbitkan.

Haryono. (2009). Prevalensi Gangguan Tidur pada Remaja Usia 12-15 Tahun di Sekolah Lanjutan Tingkat Pertama. Jurnal Sari Pediatri, Vol. 11, No. 3, Oktober 2009.

Kariyadi P. (2015). Dampak Teknologi Gadget Terhadap Perkembangan Remaja. Diakses dari https://id.scribd.com/doc/274502617/Dampak-Teknologi-Gadget-TerhadapPerkembangan- Remaja. pada tanggal 04 April 2020.

Kemkominfo. (2017). Riset Kominfo dan UNICEF Mengenai Perilaku Anak dan Remaja Dalam Menggunakan Internet. Diakses dari https://kominfo.go.id/index.php/content/detail/3834/Siaran+Pers+No.+17-PIH KOMINFO-2

2014+tentang+Riset+Kominfo+dan+UNICEF+Mengenai+Perilaku+Anak+dan+Remaja+ Dala $\mathrm{m}+$ Menggunakan+Internet+/0/siaran_pers//

Linggasari, Yohannie. (2014). Penelitian Kesehatan: Banyak Remaja Kurang Tidur Karena Gadget- nya. Diakses melalui https://www.cnnindonesia.com/gayahidup/20141117170043-255-12049/banyak-remaja-kurang-tidur-karena-gadget-nya

Notoadmodjo, (2014). Metodologi Penelitian Keperawatan. Jakarta: Rineka Cipta.

Permadi. (2017). Hubungan Perilaku Penggunaan Gadget Dengan Kualitas Tidur Pada Anak Usia Remaja di SMA Negeri 1 Srandakan Bantul. Jurnal Unisa Tahun 2017. Tidak diterbitkan. Potter \& Perry. 2010. Fundamental Of Nursing edisi 7. Jakarta: Salemba Medika

Widiawati, I, Sugiman, H \& Edy.(2014). Pengaruh Penggunaan Gadget Terhadap Daya Kembang Anak. Jakarta: Universitas Budi Luhur. E-journal 